\section{Systemic amyloid associated with carcinoma of the bronchus}

\author{
I Richmond, P S Hasleton, S Samadian
}

\begin{abstract}
An association of systemic amyloid with a squamous cell carcinoma of the bronchus is described. Amyloid may be associated with myeloma and neuroendocrine tumours ${ }^{1}$ but has not been described in squamous cell carcinoma of the bronchus.
\end{abstract}

\section{Case report}

A 72 year old man with no previous medical history was admitted with a 10 week history of watery diarrhoea and weight loss and a three day history of haemoptysis. He also complained of vague chest and upper abdominal discomfort. The nails were clubbed. A chest radiograph showed a solitary right upper lobe

Dr P S Hasleton,

Wythenshawe Hospital,

Manchester M23 9LT.

Accepted 3 October 1989

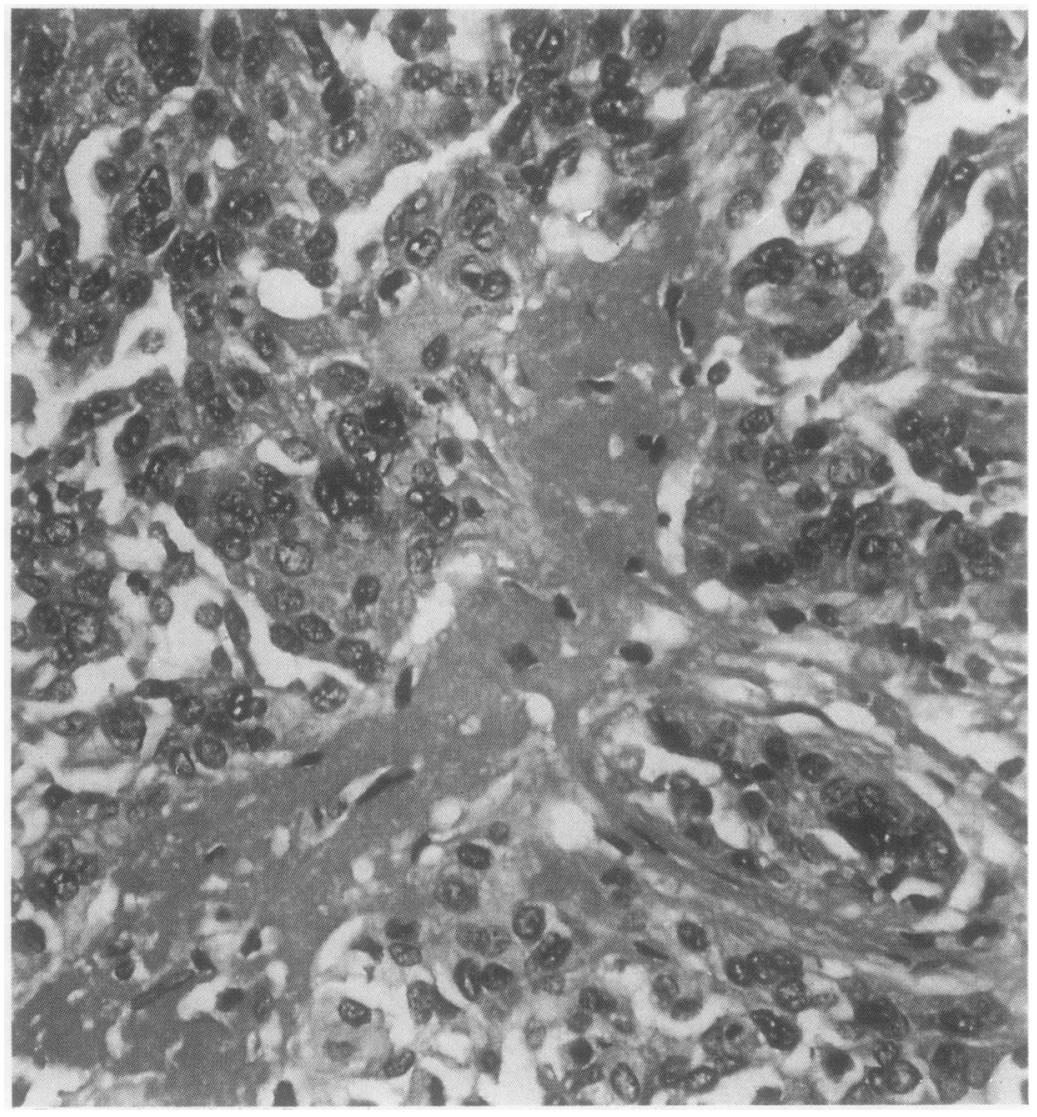

$A$ rather necrotic, poorly differentiated squamous cell carcinoma containing deposits of amyloid. (Sulphated alcian blue-van Gieson.) mass suggesting a primary bronchial neoplasm. Sigmoidoscopy disclosed a red, haemorrhagic mucosa and biopsy showed submucosal amyloid in and around vessels.

Ultrasound examination of the abdomen showed a large epigastric mass, thought to be pancreatic in origin. The patient died after developing peritonism and renal failure.

At necropsy a necrotic tumour $(4 \times 5 \mathrm{~cm})$ was found in the right upper lobe, with a distal abscess cavity. There was no bronchiectasis. Both small and large intestines had a patchy red mucosa, most noticeable in the caecum and the transverse and sigmoid colon. Both kidneys showed considerable cortical pallor. No pancreatic mass was found.

Haematoxylin and eosin, Congo red, and sulphated alcian blue-van Gieson staining confirmed that amyloid was present in the large and small bowel, and also in the adrenal glands, liver, spleen, kidney, portal vein, and pancreatic vessels. The lung tumour was a squamous cell carcinoma that also contained nodular foci of amyloid (figure). A few deposits were noted in the lung parenchyma. Blocks from the tumour and the liver were sent to Professor MB Pepys (Royal Postgraduate School, London) for typing. Congophilia was sensitive to potassium permanganate pretreatment. Immunohistochemical studies gave positive results. Both trypsinised and nontrypsinised tumour stained with antiserum amyloid component, and absorption of the antibody with antiserum amyloid component abolished this staining. The amyloid in both tissues (lung tumour and liver) stained with antiserum amyloid A protein, the staining being abolished when antiserum was absorbed. The amyloid was thus typed as AA.

\section{Discussion}

Amyloid is a faintly eosinophilic material deposited between cells in various tissues and organs in various clinical conditions. Two major, chemically distinct classes of amyloid fibril proteins have been identified; one, amyloid light chain (AL), is derived from plasma cells and contains immunoglobulin light chains; the other (amyloid associated, AA) is a unique immunoglobulin synthesised by the liver. Several other biochemically distinct proteins have been found in amyloid deposits. ${ }^{2}$

Amyloid in a localised form associated with tumours is usually AL (or sometimes, with endocrine tumours, procalcitonin). Systemic (AA) amyloid, present in our case, has been described in hypernephroma ${ }^{3}$ and in an unusual peritoneal mesothelioma. ${ }^{4}$ Some series have reported systemic amyloidosis associated with malignancy but they were studied before amyloid typing was available. In a necropsy series amyloid occurred in $6.1 \%$ of bronchogenic carcinomas. ${ }^{5}$ Unfortunately, histological type was not mentioned. This is important as amyloidosis may be associated with pulmonary carcinoid tumours. Amyloid has been seen in bronchial squamous cell carcinoma in rabbits exposed to benzpyrene but not in man. ${ }^{6}$

An abscess cavity was noted distal to the 
tumour. This regional cardiothoracic referral centre examined 310 cases of squamous cell carcinoma in 1988, and although many showed a distal obstructive pneumonitis there was no evidence of amyloidosis in the adjacent lung.

Raised concentrations of serum amyloid protein $A$ in serum (this is antigenically similar to AA amyloid) have been described in pulmonary carcinoma. ${ }^{7}$ It has been suggested that this might be used to diagnose tumour recurrence, though its widespread presence as an acute phase reactant may limit its value. Most patients with persistently high concentrations of serum amyloid A, such as patients with rheumatoid disease, do not develop amyloidosis, which suggests that other influences, genetic or acquired, are important.
We wish to thank Professor M B Pepys for his assistance in typing the amyloid deposits.

1 Pearse AGE, Ewen SWB, Polak JM. The genesis of apudamyloid in endocrine polypeptide tumours: histochemical distinction from immunamyloid. Virchows Arch 1972;10:93-107.

2 Cotran RS, Kumar V, Robbins SL. Robbins' Pathologic basis of disease, 4th ed. Philadelphia: Saunders, 1989:210-6.

3 Hind CRK, Tennent GA, Evans DJ, Pepys MB. Demonstration of amyloid A (AA) protein and amyloid P component (AP) in deposits in systemic amyloidosis component (AP) in deposits in systemic amyloidosis 139:159-66.

4 Husby G, Marhang G, Sletten K. Amyloid A in systemic amyloidosis associated with cancer. Cancer Res 1982; 42:1600-3.

5 Kimball KG. Amyloidosis in association with neoplastic disease. Ann Intern Med 1961;55:958-74.

6 Hirao F, Nishikawa H, Yoshimoto T, et al. Production of lung cancer and amyloidosis in rabbits by intrabronchial instillation of benzopyrene. Gan 1980;71:197-205.

7 Benson MD, Cohen AS. Serum amyloid A protein in amyloidosis, rheumatic and neoplastic diseases. Arth Rheum 1979;22:36-42. 